\title{
Analysis of risk indicators for prevalence of peri-implant diseases in Turkish population
}

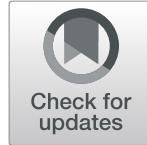

Sadiye Gunpinar ${ }^{*}$, Bilge Meraci and Mert Karas

\begin{abstract}
Background: The aim of this cross-sectional study was (1) to determine the prevalence of peri-implant mucositis and peri-implantitis and (2) to reveal the risk indicators associated with peri-implant diseases. The second point was to investigate the role of keratinized mucosa on peri-implant health.

Materials and methods: Three hundred and eighty-two subjects who were treated with 1415 dental implants between 2011-2017 were clinically evaluated. Patients' medical and dental history, as well as implant details, were recorded. Periimplant examination included probing pocket depth (PPD), bleeding on probing (BoP), plaque index (PI), gingival index (GI), and keratinized tissue width. Furthermore, the patient (sex, age, and smoking) and implant/prosthesis-related factors (surface characteristic, time in function, design of prosthesis etc.) were evaluated. Implants were classified into three groups: healthy, peri-implant mucositis, and peri-implantitis. Uni- and multi-variate regression analyses were utilized for statistics.
\end{abstract}

Results: $41.1 \%(n=157)$ and $36.9 \%(n=84)$ of patients had mucositis and peri-implantitis, respectively. 53.6\% $(n=758)$ of implants (95\%Cl 80.2-90.4) had mucositis, and 21.7\% $(n=307)$ had peri-implantitis. Patients with a maintenance $<2 /$ year $(\mathrm{OR}=2.576)$, having periodontitis $(\mathrm{OR}=3.342)$ and higher $\mathrm{PI}(\mathrm{OR}=3.046)$ had significant associations with the development of peri-implant mucositis. Significant ORs were determined for peri-implantitis with patients having maintenance $<2 /$ year $(\mathrm{OR}=2.048)$, having number of implants $\geq 4(\mathrm{OR}=2.103)$, diagnosed with periodontitis $(\mathrm{OR}=$ 3.295), and higher PI (OR = 7.055). Keratinized tissue width $<2 \mathrm{~mm}(\mathrm{ORs}=5389 / 8.013), \mathrm{PPD}(\mathrm{ORs}=1.570 / 8.338), \mathrm{PI}(\mathrm{ORs}=$ 6.726/5.205), and BoP (ORs = 3.645/4.353) independent variables were significantly associated with both peri-implant mucositis and peri-implantitis at implant level, respectively.

Conclusions: Within the limits of this study, the prevalence of mucositis and peri-implantitis was shown to be high in Turkish population. Furthermore, increased risk for peri-implantitis was identified in patients having maintenance $<2 /$ year, presence of periodontitis, poor plaque control, and having number of implants $\geq 4$. Less keratinized tissue $(<2 \mathrm{~mm}), \mathrm{PPD}$, and BoP were also risk indicators for peri-implantitis development.

Keywords: Peri-implant diseases, Peri-implant mucositis, Peri-implantitis, Keratinized mucosa, Prevalence, Risk indicators

\section{Introduction}

Peri-implant mucositis is identified as an inflammatory state which only affects soft tissue around implants. On the other hand, peri-implantitis affects both soft and hard tissue and is characterized with progressive loss of alveolar bone [1]. There is growing interest for researchers to investigate the peri-implant diseases

* Correspondence: coskunersadiye@gmail.com

Department of Periodontology, Faculty of Dentistry, Bolu Abant Izzet Baysal University, Bolu, Turkey

Springer Open including both peri-implant mucositis and periimplantitis because of increasing high prevalence [2-4].

Peri-implant diseases are initiated by microbial dental biofilm similarly to periodontal diseases including gingivitis and periodontitis [1]. Current literature supports that succesful treatment of periodontal diseases can be achieved more handily; however, once the peri-implant supporting tissues are lost, then regeneration of soft and hard tissues could not be possible $[5,6]$. Therefore, prevention of peri-implant diseases are more essential and

(c) The Author(s). 2020 Open Access This article is licensed under a Creative Commons Attribution 4.0 International License, which permits use, sharing, adaptation, distribution and reproduction in any medium or format, as long as you give appropriate credit to the original author(s) and the source, provide a link to the Creative Commons licence, and indicate if changes were made. The images or other third party material in this article are included in the article's Creative Commons licence, unless indicated otherwise in a credit line to the material. If material is not included in the article's Creative Commons licence and your intended use is not permitted by statutory regulation or exceeds the permitted use, you will need to obtain permission directly from the copyright holder. To view a copy of this licence, visit http://creativecommons.org/licenses/by/4.0/. 
important than treatment, to increase the success rate of the implant for long-term.

Knowledge of the factors that lead to peri-implant disease is crucial for maintaining the dental implants to function properly. Several patient- and implant-related risk indicators including poor oral hygiene, smoking, history of periodontal disease, and compliance of maintenance have been reported $[2-4,7]$. On the other hand, the necessity of keratinized tissue around implant is controversial. Some researchers reported that insufficient or an absence of keratinized mucosa $(\mathrm{KM})$ is related to increased plaque accumulation and inflammatory parameters around implants $[2,8-10]$, others did not find a necessity for KM width to maintain peri-implant health [11-13]. In a systematic review, the presence of at least 1 to 2 -mm width of $\mathrm{KM}$ might be crucial for maintenance of peri-implant stability [14]. Besides, Wennstrom and Derks [15] reported that the need for keratinized mucosa was limited to maintain peri-implant soft and hard tissue stability. Furthermore, a threshold value for the presence of KM width, whether 1 $\mathrm{mm}$ or $2 \mathrm{~mm}$, is not available in the literature. Recently, Lim et al. [13] investigated the influence of KM on periimplant health and concluded that in compliant subjects, the width of KM may not be necessary to maintain periimplant health. In addition, they could not identify a thereshold value for the need of KM width.

In the shed of these findings, the purpose of this crosssectional study is to determine the prevalence of periimplant diseases and to clarify the probable systemic and local risk indicators related to peri-implant health in subjects treated in a university periodontology clinic.

\section{Materıals and methods}

\section{Study design}

The present cross-sectional study was conducted in Periodontology Department, in Bolu Abant Izzet Baysal University. Patients received dental implant treatment and implant-supported prosthetic rehabilitation between 20112016 by one trained and experienced periodontology specialist (SG) and by three research assistants under the supervision of the same experienced periodontology specialist (SG). The patients were recalled for re-evaluations which included clinical examinations since June 2017.

The methodology of the study was approved by the ethics committee in human research from the School of Medicine, Bolu Abant Izzet Baysal University (decision number: 2017/175). Before the study, each patient was verbally informed about the procedures, and signed informed consent was obtained.

\section{Study population}

\section{Inclusion and exclusion criteria}

Patients ( $>18$ years old) rehabilitated with one or more dental implants, with at least 12 months of follow-up after loading, had panoramic radiograph immediately after surgery, and received regular or irregular maintenance therapy at the same periodontology department where the implants had been surgically inserted were included in this study. Individuals previously diagnosed with aggressive periodontitis [16]; had inadequate radiograph; had received administration of bisphosphonates and immunosuppressive medications, or antibiotic therapies in the previous 6 months were excluded. Pregnant or lactating women and subjects who had other missing data were also excluded.

\section{Outcome measures \\ Clinical parameters}

For each subject, age, gender, periodontal diagnosis (healthy, gingivitis, periodontitis) (17), presence of systemic diseases (cardiovascular disease, hypertension, or diabetes), drug intake, number of dental implants, and frequency of maintenance (at least two maintenance appointments per year/less than two per year or none) were recorded. Smoking habit was also recorded and categorized as non-smoker (subjects who never smoke or quit smoking for at least 5 years) and current smoker ( $<10$ cigarettes/day or $\geq 10$ cigarettes/day).

For each implant, the following data were collected: location (anterior/posterior, maxilla/mandible), time in function (months), implant brand, type of prosthesis (fixed-multiple/single or removable) and previous bone augmentation procedure (yes/no).

The following peri-implant clinical parameters were recorded: probing pocket depth (PPD) in six sites per implant, plaque index (PI) [18] and gingival index (GI) [19] in four sites per implant (vestibul-lingual/palatinalmesial-distal), bleeding on probing (BoP) measured as presence/absence at six sites per implant, and width of keratinized mucosa (KM). KM was measured in millimeter at three points (1-mm mesial-midpoint and 1-mm distal of buccal site) between gingival margin and mucogingival line. Mucogingival junction was determined by mobility test, and the mean of those three measurements was recorded as $K M(0-2 \mathrm{~mm} / \geq 2 \mathrm{~mm})$.

Patients with periodontitis were defined as the existence of periodontal pocket depths $\geq 4 \mathrm{~mm}$ with BoP and clinical attachment loss $>2 \mathrm{~mm}$ in at least two nonadjacent interproximal area [17]. All clinical assessments were performed by a single and previously calibrated investigator (M.K.), using a manual periodontal probe (PCP-UNC 15: Hu-Friedy, Chicago, IL, USA). Intraexaminer calibration were performed in ten individuals not participating in the study presenting peri-implant mucositis and peri-implantitis. PPD values were recorded on six surfaces, and GI scores were recorded on four surfaces of each implant, in two separate sessions, $48 \mathrm{~h}$ apart. The intraclass correlation coefficients ranged 
between 0.811 and 0.923 for PPD, and the Cohen's kappa (к) value of GI was 0.824 .

\section{Case definition}

Peri-implant health was defined as absence of bleeding and/or suppuration on probing and no detectable radiographic marginal bone loss after initial bone remodeling. Peri-implant mucositis was diagnosed as tissue edema with bleeding on probing and absence of bone loss after initial crestal bone remodeling. On the other hand, diagnosis of peri-implantitis was based on the presence of bleeding and/or suppuration on probing, probing depth $>5 \mathrm{~mm}$, and marginal bone loss $>2 \mathrm{~mm}$ reference to the most coronal part of the implant [1].

The implant with the most severe clinical diagnosis was chosen to describe the patient diagnosis. Accordingly, an individual was diagnosed as having periimplantitis if at least one implant had the diagnosis of peri-implantitis, and an individual was diagnosed as having peri-implant mucositis if one or more implant had the diagnosis of peri-implant mucositis.

\section{Statistical analysis}

Descriptive statistics are presented as frequencies and percentages. The prevalence of peri-implant health, periimplant mucositis, and peri-implantitis were reported at implant and patient levels. Risk indicators for periimplant mucositis and peri-implantitis were analyzed. For all models, the odds ratio (OR) and the 95\% confidence intervals $(\mathrm{CI})$ were reported.

Univariate logistic regression analysis was conducted for each independent variable individually to determine factors associated with peri-implant mucositis and periimplantitis. Factors with a combination of $p$ values < 0.05 were chosen for the multivariate logistic regression. To avoid multicollinearity, Spearman's correlation analysis was used. Accordingly, implant-related independent variables GI and BoP $(p=0.000, r=0.859)$ and dental arch and implant position $(p=0.000, r=0.908)$ showed strong correlations. Therefore, after univariate regression, BoP and implant position independent variables were included in the final multivariate regression model. The statistical software SPSS (IBM, Version 22.0, Armonk, NY) was used for all analyses, and statistical differences with $p$ values $<0.05$ were considered significant. All the statistical results obtained from SPSS were confirmed with $\mathrm{R}$ statistics, and the results from SPSS were utilized in the tables.

\section{Results}

Demografic and clinical evaluation

A group of 424 patients were evaluated for inclusion, out of which, 42 patients were excluded. Among these, 36 had implants with $<1$ year of follow-up from prosthetic loading, and six were pregnant. The patientand implant-related demographics and clinical parameters are shown in Tables 1 and 2. Three hundred eighty two patients (175 male and 207 female) with 1415 dental implants participated and clinically evaluated in this study.

The mean age of the patients was $51.66 \pm 12.16$ years, ranging from 24 to 78 years. The mean follow-up was $3.79 \pm 1.48$ years (45.50 \pm 17.78 months). Moreover, 97.1\% ( $n=1374)$ of implants had $\geq 2$ years of follow-up, $70 \%(n=990)$ had $\geq 3$ years, and $41.1 \%(n=582)$ had $\geq$ 4 years. The percentage of implants with more than 5 years of follow-up was $15 \%(n=212)$.

In the medical history, systemic diseases were reported for $29.6 \%(n=113)$ and diabetes were $11.8 \%(n=45)$ of patients. Smokers were $34 \%(n=130)$ of the sample. The majority of the patients $(67.8 \%)$ had fair oral hygiene presenting a FMPI $>1(n=259)$, and $63.1 \%$ of the patients had periodontitis. Gingivitis was diagnosed in $17.8 \%$ of the study population, and $19.1 \%$ showed healthy tissues.

A total of 1415 implants were examined in this study: $46.1 \%$ in the maxilla and $53.9 \%$ in the mandible. The average PPD was $3.54 \pm 1.53 \mathrm{~mm}(3.30 \pm 0.91$ for

Table 1 Patient-related categorical data analyzed in this study

\begin{tabular}{|c|c|c|}
\hline \multirow{2}{*}{$\begin{array}{l}\text { Patient-related } \\
\text { data }\end{array}$} & \multicolumn{2}{|l|}{$N=382$} \\
\hline & $n$ & $\%$ \\
\hline \multicolumn{3}{|l|}{ Gender } \\
\hline Female/Male & $207 / 175$ & $54.2 / 45.8$ \\
\hline \multicolumn{3}{|l|}{ Smoking } \\
\hline Non-smoker & 252 & 66.0 \\
\hline Smoker $(\geq 10)$ & 130 & 34.0 \\
\hline \multicolumn{3}{|l|}{ Systemic disease } \\
\hline Yes/No & $113 / 269$ & 29.6/70.4 \\
\hline \multicolumn{3}{|l|}{ Diabetes } \\
\hline Yes/No & $45 / 337$ & $11.8 / 88.2$ \\
\hline \multicolumn{3}{|c|}{ Periodontal diagnosis } \\
\hline Healthy & 73 & 19.1 \\
\hline Gingivitis & 68 & 17.8 \\
\hline Periodontitis & 241 & 63.1 \\
\hline \multicolumn{3}{|l|}{ FMPI } \\
\hline$>1$ & 259 & 67.8 \\
\hline$\leq 1$ & 123 & 32.2 \\
\hline \multicolumn{3}{|c|}{ Number of implants } \\
\hline$\geq 4$ & 151 & 39.5 \\
\hline$<4$ & 231 & 60.5 \\
\hline \multicolumn{3}{|c|}{ Frequency of maintenance/year } \\
\hline$<2$ & 219 & 57.3 \\
\hline$\geq 2$ & 163 & 42.7 \\
\hline
\end{tabular}

FMPI full-mouth plaque index 
Table 2 Implant-related data analyzed in this study

\begin{tabular}{|c|c|c|}
\hline \multirow[t]{2}{*}{ Implant-related data } & \multicolumn{2}{|l|}{$N=1415$} \\
\hline & $n$ & $\%$ \\
\hline \multicolumn{3}{|l|}{ Dental arch } \\
\hline Maxilla/mandibula & $653 / 762$ & $46.1 / 53.9$ \\
\hline \multicolumn{3}{|l|}{ Position } \\
\hline Maxilla anterior & 169 & 11.9 \\
\hline Maxilla posterior & 483 & 34.1 \\
\hline Mandibula anterior & 219 & 15.5 \\
\hline Mandibula posterior & 544 & 38.4 \\
\hline \multicolumn{3}{|l|}{ Keratinized tissue width } \\
\hline$<2 \mathrm{~mm}$ & 542 & 38.3 \\
\hline$\geq 2 \mathrm{~mm}$ & 873 & 61.7 \\
\hline \multicolumn{3}{|l|}{ Bone grafting } \\
\hline Yes/No & $214 / 1201$ & $15.1 / 84.9$ \\
\hline \multicolumn{3}{|l|}{ Periodontal diagnosis } \\
\hline Healthy & 204 & 14.4 \\
\hline Gingivitis & 188 & 13.3 \\
\hline Periodontitis & 1023 & 72.3 \\
\hline \multicolumn{3}{|l|}{ Type of prosthesis } \\
\hline Removable/fixed & $236 / 1179$ & 16.7/83.3 \\
\hline \multicolumn{3}{|l|}{ Brand } \\
\hline । & 408 & 28.8 \\
\hline$\|$ & 184 & 13.0 \\
\hline III & 514 & 36.3 \\
\hline IV & 188 & 13.3 \\
\hline V & 121 & 8.6 \\
\hline \multicolumn{3}{|l|}{ Years from loading } \\
\hline$>24$ months & 1374 & 97.1 \\
\hline
\end{tabular}

mucositis; $5.57 \pm 1.44$ for peri-implantitis), and the average PI was $1.44 \pm 0.69$ (1.66 \pm 0.55 for mucositis; $1.84 \pm$ 0.38 for peri-implantitis). The mean presence of bleeding was detected $50.49 \%$ (63.25\% in mucositis and $73.19 \%$ in peri-implantitis). The keratinized tissue width around the implant was $<2 \mathrm{~mm}$ in $38.3 \%$ of the implants and also $3.9 \%$ of implants had absence of keratinized mucosa.

\section{Prevalence of peri-implant mucositis and peri-implantitis}

Twenty-two percent of the patients $(n=84)$ showed healthy peri-implant mucosa. $41.1 \%(n=157)$ of the patients presented peri-implant mucositis, whereas $36.9 \%$ ( $n=$ 141) exhibited peri-implantitis. Corresponding values were $12.6 \%(n=19)$; $43.0 \%(n=65)$; and $44.4 \%(n=67)$ in subjects who had $\geq 4$ number of implants.

Implant level analyses revealed that $24.7 \%$ of the implants $(n=350)$ presented no signs of peri-implant diseases. Furthermore, the prevalence of peri-implant mucositis and peri-implantitis at the implant level was $53.6 \%(n=758)$ and $21.7 \%(n=307)$, respectively (Table 3$)$.

\section{Risk indicators for peri-implant mucositis and peri- implantitis \\ Patient level}

Table 4 depicts the ORs and 95\% CI for each patientbased factor associated with peri-implant mucositis and peri-implantitis. According to the univariate regression analysis, age, frequency of maintenance, systemic disease, periodontal disease (periodontitis versus gingivitis/ healthy), number of dental implants, and PI were significantly associated with peri-implant mucositis. In the multivariate regression model using these significant variables, frequency of maintenance $(\mathrm{OR}=2.576,95 \% \mathrm{CI}$ 1.403-4.729; $p=0.002$ ), periodontal disease (having periodontitis $)(\mathrm{OR}=3.342,95 \% \mathrm{CI} 1.702-6.561 ; p=$ $0.000)$, and PI (OR $=3.046,95 \%$ CI 1.724-5.383; $p=$ 0.000 ) had significant associations with the development of peri-implant mucositis.

When the variables were analyzed with regard to periimplantitis development at patient level, only gender did not reach statistical significance $(\mathrm{OR}=0.577,95 \% \mathrm{CI}$ $0.332-1.002 ; p=0.051)$. Instead, multivariate regression showed that PI was significantly associated with periimplantitis development $(\mathrm{OR}=7.055$, 95\% CI 3.80313.088; $p=0.000)$. Furthermore, significant ORs were determined for patients having maintenance per year $<2$ $(\mathrm{OR}=2.048,95 \%$ CI 1.074-3.907; $p=0.030)$, patients having $\geq 4$ implants $(\mathrm{OR}=2.103,95 \%$ CI 1.040-4.251; $p$ $=0.039)$, patients diagnosed with periodontitis $(\mathrm{OR}=$ 3.295 , 95\% CI 1.593-6.815; $p=0.001$ ) via multivariate regression model.

\section{Implant level}

The implant-based variables associated with periimplant mucositis and peri-implantitis are summarized in Table 5. The significant variables obtained by univariate regression were utilized for multivariate regression. Accordingly, having a systemic disease (ORs $=2.196$ / $3.789)$, diagnosed as periodontitis (ORs $=6.931 / 18.613)$, keratinized tissue width $<2 \mathrm{~mm}$ (ORs $=5.389 / 8.013)$, PPD (ORs $=1.570 / 8.338)$, PI (ORs $=6.726 / 5.205)$, and $\mathrm{BoP}(\mathrm{ORs}=3.645 / 4.353)$ independent variables were significantly associated with both peri-implant mucositis and peri-implantitis, respectively.

\section{Discussion}

The present non-interventional study evaluated the frequency of peri-implant diseases and probable risk indicators of both peri-implant mucositis and periimplantitis in patients applied to a university periodontology department. 
Table 3 Prevalence of peri-implant health and disease at patient and implant levels

\begin{tabular}{llll}
\hline & \multicolumn{2}{c}{ Patient level $(N=382)$} & Implant level $(N=1415)$ \\
\cline { 2 - 4 } & $\%(n)$ & $28.1(65) / 12.6(19)$ & $24.7(350)$ \\
\hline Peri-implant health & $22.0(84)$ & $39.8(92) / 43.0(65)$ & $53.6(758)$ \\
Peri-implant mucositis & $41.1(157)$ & $32.0(74) / 44.4(67)$ & $21.7(307)$ \\
Peri-implantitis & $36.9(141)$ & Number of implants $1-3 / \geq 4, \%(n)$ & \\
\hline
\end{tabular}

This study included a total of 382 subjects, with 1415 implants. Peri-implant mucositis was defined as the presence of BoP without bone loss after initial remodeling as suggested and as in line with the literature $[1,20$, $21]$. But the definition of peri-implantitis vary across the studies. Some studies diagnose peri-implantitis according to the bone level changes with reference to the exposed implant thread [22-24]; others agree for the marginal bone loss in millimeters ranging from 0.5 to 5 $\mathrm{mm}$ as threshold $[2,3,25,26]$. Therefore, different case definitions and different thresholds cause wide range of the prevalences of peri-implant diseases. In our study, the peri-implantitis was diagnosed as having $>2 \mathrm{~mm}$ marginal bone loss, > $5 \mathrm{~mm}$ PPD with BoP and the prevalence of patients presenting peri-implant mucositis and peri-implantitis were $41.1 \%$ and $36.9 \%$, respectively. The prevalence increases to $43.0 \%$ for peri-implant mucositis and $44.4 \%$ for peri-implantitis in patients having number of implants $\geq 4$. When we analyze the results at implant levels, the prevalences were determined as $53.6 \%$ and $21.7 \%$ for peri-implant mucositis and periimplantitis, respectively. These results are similar to some studies [26-29]. On the other hand, compared to other studies, these prevalences are relatively high in which the prevalence of peri-implantitis ranges from 1-
$15.8 \%[2,25,30-32]$ at patient level. These different results could be attributed to the characteristics of the study population including having different probable risk factors for peri-implant diseases development and also the different case definitions. Furthermore, reporting the prevalences as subject or implant level is making it difficult to compare the results with the literature. But, general opinion is that the prevalences of peri-implant diseases should be assessed at subject level as in other chronic systemic diseases [20].

Based on the results of multivariable multinomial regression analysis, frequency of maintenance $<2$ year $(\mathrm{OD}=2.57 ; 2.04)$, patients diagnosed as periodontitis $(\mathrm{OD}=3.31 ; 3.29)$, and PI $(\mathrm{OD}=3.04 ; 7.05)$ were associated with peri-implant mucositis and peri-implantitis development at patient level, respectively. In addition to these results, patients who have $\geq 4$ number of implants have higher risk for peri-implantitis occurrence (OD = 2.10) than patients having number of implants $<4$ as reported in numerous studies [3, 22, 33-35]. These results are in agreement with the literature as follows: higher PI (which also demonstrates poor oral hygiene) [27, 30,36], patients who do not participate to the maintenance therapy $[7,37]$, and patients who had history of periodontitis were demonstrated as risk indicators for the

Table 4 Patient-related probable risk indicators for the occurrence of peri-implant mucositis and peri-implantitis

\begin{tabular}{|c|c|c|c|c|c|c|c|c|c|c|c|c|c|}
\hline \multirow[t]{3}{*}{ Variable } & & \multicolumn{6}{|c|}{ Peri-implant mucositis } & \multicolumn{6}{|c|}{ Peri-implantitis } \\
\hline & & \multicolumn{3}{|c|}{ Univariate regression } & \multicolumn{3}{|c|}{ Multivariate regression } & \multicolumn{3}{|c|}{ Univariate regression } & \multicolumn{3}{|c|}{ Multivariate regression } \\
\hline & & $\mathrm{OR}$ & $95 \% \mathrm{Cl}$ & $p$ & $\mathrm{OR}$ & $95 \% \mathrm{Cl}$ & $p$ & $\mathrm{OR}$ & $95 \% \mathrm{Cl}$ & $p$ & $\mathrm{OR}$ & $95 \% \mathrm{Cl}$ & $p$ \\
\hline Gender & Female & 0.673 & $(0.391-1.158)$ & 0.153 & & & & 0.577 & $(0.332-1.002)$ & 0.051 & & & \\
\hline Age & & 1.056 & $(1.032-1.080)$ & $0.000^{*}$ & & & & 1.047 & $(1.023-1.071)$ & $0.000^{*}$ & & & \\
\hline Smoking & Yes & 1.179 & $(0.638-2.179)$ & 0.599 & & & & 2.981 & $(1.634-5.437)$ & $0.000^{*}$ & & & \\
\hline $\begin{array}{l}\text { Frequency of } \\
\text { maintenance/ } \\
\text { year }\end{array}$ & $<2$ & 2.866 & $(1.659-4.953)$ & $0.000^{*}$ & 2.576 & $(1.403-4.729)$ & $0.002^{*}$ & 2.278 & $(1.311-3.956)$ & $0.003^{*}$ & 2.048 & $(1.074-3.907)$ & $0.030^{*}$ \\
\hline $\begin{array}{l}\text { Systemic } \\
\text { disease }\end{array}$ & Yes & 1.965 & $(1.021-3.782)$ & 0.043 & & & & 2.697 & $(1.353-5.021)$ & $0.004^{*}$ & & & \\
\hline Diabetes & Yes & 1.426 & $(0.491-4.147)$ & 0.514 & & & & 3.742 & $(1.382-10.136)$ & $0.009^{*}$ & & & \\
\hline $\begin{array}{l}\text { Periodontal } \\
\text { disease }\end{array}$ & Periodontitis & 5.874 & $(3.283-10.509)$ & $0.000^{*}$ & 3.342 & $(1.702-6.561)$ & $0.000^{*}$ & 6.634 & $(3.642-12.082)$ & $0.000^{*}$ & 3.295 & $(1.593-6.815)$ & $0.001^{*}$ \\
\hline $\begin{array}{l}\text { Number of } \\
\text { implants }\end{array}$ & $>4$ & 2.417 & $(1.324-4.412)$ & $0.004^{*}$ & & & & 3.097 & $(1.685-5.693)$ & $0.000^{*}$ & 2.103 & $(1.040-4.251)$ & $0.039^{*}$ \\
\hline PI & & 3.362 & $(2.038-5.546)$ & $0.000^{*}$ & 3.046 & $(1.724-5.383)$ & $0.000^{*}$ & 8.365 & $(4.769-14.670)$ & $0.000^{*}$ & 7.055 & (3.803-13.088) & $0.000^{*}$ \\
\hline
\end{tabular}




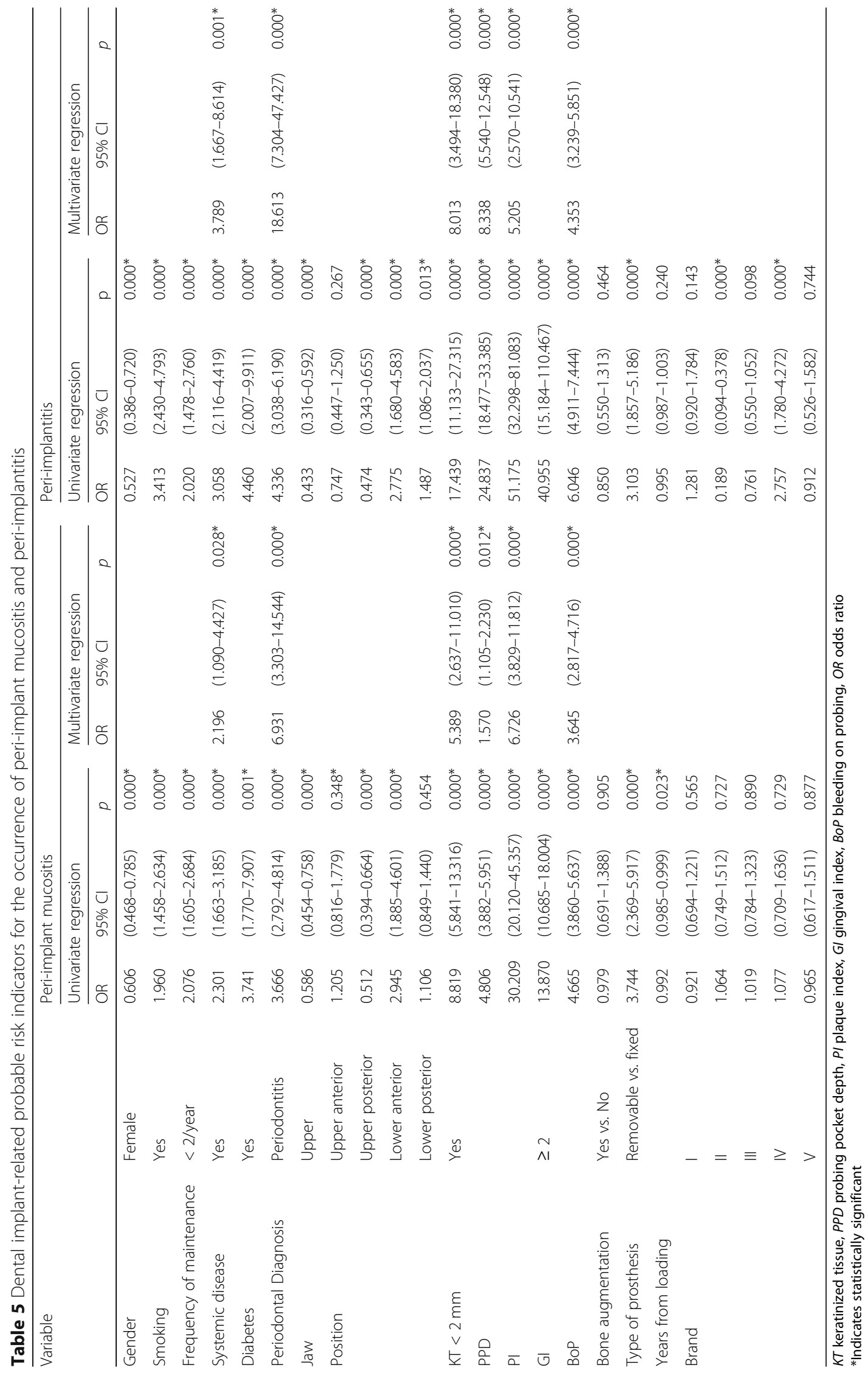


development of peri-implant disease [4, 33, 38]. In this cross sectional study, patients who have current diagnosis of periodontitis had increased probability for development of peri-implant disease. Therefore, our results are significant to reveal the importance of current periodontal status as a risk indicator.

When the putative risk indicators for peri-implant disease were analyzed at implant level, it was determined that, in addition to PI and periodontitis diagnosis, higher PPD, and BoP, having a systemic disease and keratinized tissue (KT) width $<2 \mathrm{~mm}$ were associated with both peri-implant mucositis and peri-implantitis occurrence. Among these variables, PI, PPD, BoP, and current periodontitis diagnosis are relatively predicted variables, but systemic disease and KT width are controversial. In our study, patients with systemic diseases (cardiovascular disease, hypertension, and diabetes) have increased risk for mucositis $(\mathrm{OD}=2.1)$ and peri-implantitis $(\mathrm{OD}=3.7)$ development than patients who were systemically healthy. On the other hand, when diabetes was analyzed solely as an indicator rather than having a systemic disease, multivariate anayses did not find an association with the peri-implant disease development. Conversely, Monje et al. [39] reported that patients with diabetes were at high risk for peri-implantitis development but not for peri-implant mucositis. Furthermore, implant survival rates were reported as high in patients who were taking antihypertensive drugs than systemically healthy subjects [40]. In our study, drug usage could not be analyzed because of presenting multicolinerity with the variable sytemic disease data. These results could be attributed to the patients with diabetes and might be relatively more under controlled than patients with HT and having cardiovascular disease. Besides, self-reported patients' medical history was recorded. The hemoglobin A1c (HbA1c) levels were not measured in patients with diabetes.

In the literature, there is no consensus about the KT width around dental implant, whether necessary or not. Additionally, the adequate width of KT is controversial. Several researchers reported that KT is not necessary to maintain peri-implant tissue health [11, 12]. Conversely, in line with our results, the necessity of KT around implant-supported prostheses have been shown to be essential for proper plaque control [41]. Unexpectedly, Pimentel et al. [35] and Roos-Jansaker et al. [42] demonstrated that presence of $\mathrm{KT}$ is associated with periimplant inflammation. In our study, implants with $\mathrm{KT}<$ $2 \mathrm{~mm}$ have greater change for peri-implant mucositis $(\mathrm{OD}=5.38)$ and peri-implantitis $(\mathrm{OD}=8.01)$ development respectively, than implants having $\mathrm{KT} \geq 2 \mathrm{~mm}$. In our study, although the amount of bone loss was not evaluated, it is assumed that less $\mathrm{KT}$ is more related to the plaque accumulation rather than the bone loss around implants because higher PIs were scored in implants having $\mathrm{KT}<2 \mathrm{~mm}$ as reported in other studies [41]. The different results about the importance of KT among studies might be due to the differences in the thereshold values of KT and follow-up times considered. Furthermore, the characteristics of the study population and also the different probable risk indicators included in the analysis could be the reasons.

PPD was determined as another risk indicator for periimplant disease development in this study. This result was first reported by Vignoletti et al. [3]. They revealed that implants having PPD $\geq 4 \mathrm{~mm}$ had increased risk for peri-implantitis development $(\mathrm{OD}=3.5)$. In our crosssectional study, for each $1 \mathrm{~mm}$ increase in PPD, the OR of having peri-implant mucositis increase was 1.57 , and peri-implantitis increase was 8.33 . In the literature, increased PPD was associated with increased BoP [43] and bone loss [44]. Furthermore, increased PPD would ensure anaerobic microbial growth and this would cause soft and hard tissue breakdown [45]. On the other hand, PPD is an important criteria for diagnosis of periimplant diseases. Therefore, PPD, which was identified as a risk indicator, should be verified in the prospective studies because PPD might be a consequence rather than a risk due to the cross-sectional nature of our study.

The results of this cross-sectional study might have been effected by some limitations. Firstly, the occlusal overload and some possible risk indicators as platform switching related to the implant supported prosthesis were not evaluated. Second, patients who had given up smoking were accepted as non-smokers and only the current smoking status of the patients were considered. Therefore, this might have masked the actual effect of smoking on the development of peri-implant diseases. Third, the cross-sectional nature of our study only allows us to consider one evaluation time period rather than giving information about the progression of the disease. Thus, this limits us to make interpretation about the causality. Besides these limitations, the multilevel multivariable analyses and also both the patient- and implant-level analyses including numerous variables are the strengths of our study.

\section{Conclusıons}

Within the limitations of the present study, a high prevalence of peri-implant diseases were determined in a Turkish population rehabilitated in a university clinic. Higher probabilities of peri-implantitis were detected in patients having maintenance $<2$ year, presence of periodontitis, poor plaque control, and having number of implants $\geq 4$. Systemic disease, less keratinized tissue $(<$ $2 \mathrm{~mm}$ ), PPD, and BoP were also risk indicators for periimplantitis development. 


\section{Abbreviations}

BoP: Bleeding on probing; KM: Keratinized mucosa; PPD: Probing pocket depth; PI: Plaque index; Gl: Gingival index; OR: Odds ratio; Cl: Confidence intervals; KT: Keratinized tissue

\section{Acknowledgements}

Not applicable

\section{Authors' contributions}

$\mathrm{BM}$ and MK examined the patients and collected the data. MK transferred all the patient data to the Microsoft excel. SG analyzed the data, interpreted the results and wrote the final manuscript, and supervised all the clinical procedures. All authors read and approved the final manuscript.

\section{Funding}

This study has been self-funded by the authors.

\section{Availability of data and materials}

The datasets used and analyzed during the current study are available from the corresponding author on reasonable request.

\section{Competing interest}

The authors declare that they have no conflict of interest.

\section{Ethics approval and consent to participate}

The ethics committee of human research from the School of Medicine, Bolu Abant Izzet Baysal University (decision number: 2017/175) approved the methodology of the study. Before the study, each patient was verbally informed about the procedures, and signed informed consent was obtained.

\section{Consent for publication}

All authors have approved the manuscript and agree with its publication in International Journal of Implant Dentistry.

\section{Received: 10 February 2020 Accepted: 31 March 2020}

Published online: 20 May 2020

\section{References}

1. Berglundh T, Armitage G, Araujo MG, Avila-Ortiz G, Blanco J, Camargo PM, et al. Peri-implant diseases and conditions: consensus report of workgroup 4 of the 2017 World Workshop on the Classification of Periodontal and PeriImplant Diseases and Conditions. J Periodontol. 2018;89(Suppl 1):S313-S8.

2. Wada M, Mameno T, Onodera Y, Matsuda H, Daimon K, Ikebe K. Prevalence of peri-implant disease and risk indicators in a Japanese population with at least 3 years in function-a multicentre retrospective study. Clin Oral Implants Res. 2019;30(2):111-20.

3. Vignoletti F, Di Domenico GL, Di Martino M, Montero E, de Sanctis M. Prevalence and risk indicators of peri-implantitis in a sample of universitybased dental patients in Italy: a cross-sectional study. J Clin Periodontol. 2019;46(5):597-605.

4. Arunyanak SP, Sophon N, Tangsathian T, Supanimitkul K, Suwanwichit T, Kungsadalpipob K. The effect of factors related to periodontal status toward peri-implantitis. Clin Oral Implants Res. 2019;30(8):791-9.

5. Esposito M, Grusovin MG, Worthington HV. Treatment of peri-implantitis: what interventions are effective? A Cochrane systematic review. Eur J Oral Implantol. 2012;5(Suppl):S21-41.

6. Jepsen S, Berglundh T, Genco R, Aass AM, Demirel K, Derks J, et al. Primary prevention of peri-implantitis: managing peri-implant mucositis. J Clin Periodontol. 2015:42(Suppl 16):S152-7.

7. Rinke S, Ohl S, Ziebolz D, Lange K, Eickholz P. Prevalence of periimplant disease in partially edentulous patients: a practice-based cross-sectional study. Clin Oral Implants Res. 2011;22(8):826-33.

8. Souza AB, Tormena M, Matarazzo F, Araujo MG. The influence of periimplant keratinized mucosa on brushing discomfort and peri-implant tissue health. Clin Oral Implants Res. 2016;27(6):650-5.

9. Schrott AR, Jimenez M, Hwang JW, Fiorellini J, Weber HP. Five-year evaluation of the influence of keratinized mucosa on peri-implant soft-tissue health and stability around implants supporting full-arch mandibular fixed prostheses. Clin Oral Implants Res. 2009;20(10):1170-7.

10. Perussolo J, Souza AB, Matarazzo F, Oliveira RP, Araujo MG. Influence of the keratinized mucosa on the stability of peri-implant tissues and brushing discomfort: A 4-year follow-up study. Clin Oral Implants Res. 2018;29(12): 1177-85.

11. Dalago HR, Schuldt Filho G, Rodrigues MA, Renvert S, Bianchini MA. Risk indicators for Peri-implantitis. A cross-sectional study with 916 implants. Clin Oral Implants Res. 2017;28(2):144-50.

12. Frisch $E$, Ziebolz D, Vach $K$, Ratka-Kruger $P$. The effect of keratinized mucosa width on peri-implant outcome under supportive postimplant therapy. Clin Implant Dent Relat Res. 2015;17(Suppl 1):e236-44.

13. Lim HC, Wiedemeier DB, Hammerle CHF, Thoma DS. The amount of keratinized mucosa may not influence peri-implant health in compliant patients: a retrospective 5-year analysis. J Clin Periodontol. 2019;46(3):35462.

14. Lin $\mathrm{GH}$, Chan $\mathrm{HL}$, Wang HL. The significance of keratinized mucosa on implant health: a systematic review. J Periodontol. 2013;84(12):1755-67.

15. Wennstrom JL, Derks J. Is there a need for keratinized mucosa around implants to maintain health and tissue stability? Clin Oral Implan Res. 2012; 23:136-46.

16. Armitage GC. Development of a classification system for periodontal diseases and conditions. Ann Periodontol. 1999;4(1):1-6.

17. Papapanou PN, Sanz M, Buduneli N, Dietrich T, Feres M, Fine DH, et al. Periodontitis: consensus report of workgroup 2 of the 2017 World Workshop on the Classification of Periodontal and Peri-Implant Diseases and Conditions. J Periodontol. 2018;89(Suppl 1):S173-S82.

18. Silness J, Loe H. Periodontal Disease in Pregnancy. li. Correlation between oral hygiene and periodontal condtion. Acta Odontol Scand. 1964;22:12135.

19. Loe H. The Gingival Index, the Plaque Index and the Retention Index Systems. J Periodontol. 1967;38(6):Suppl:610-616.

20. Sanz M, Chapple IL, Working Group 4 of the VEWoP. Clinical research on peri-implant diseases: consensus report of Working Group 4. J Clin Periodontol. 2012;39 Suppl 12:202-206.

21. Peri-implant mucositis and peri-implantitis: a current understanding of their diagnoses and clinical implications. J Periodontol. 2013;84(4):436-43.

22. Derks J, Schaller D, Hakansson J, Wennstrom JL, Tomasi C, Berglundh T. Effectiveness of implant therapy analyzed in a Swedish population: prevalence of peri-implantitis. J Dent Res. 2016:95(1):43-9.

23. Renvert S, Lindahl C, Persson GR. Occurrence of cases with peri-implant mucositis or peri-implantitis in a 21-26 years follow-up study. J Clin Periodontol. 2018;45(2):233-40.

24. Mir-Mari J, Mir-Orfila P, Figueiredo R, Valmaseda-Castellon E, Gay-Escoda C. Prevalence of peri-implant diseases. A cross-sectional study based on a private practice environment. J Clin Periodontol. 2012;39(5):490-4.

25. Zetterqvist L, Feldman S, Rotter B, Vincenzi G, Wennstrom JL, Chierico A, et al. A prospective, multicenter, randomized-controlled 5-year study of hybrid and fully etched implants for the incidence of peri-implantitis. J Periodontol. 2010;81(4):493-501.

26. Daubert DM, Weinstein BF, Bordin S, Leroux BG, Flemming TF. Prevalence and predictive factors for peri-implant disease and implant failure: a crosssectional analysis. J Periodontol. 2015;86(3):337-47.

27. Konstantinidis IK, Kotsakis GA, Gerdes S, Walter MH. Cross-sectional study on the prevalence and risk indicators of peri-implant diseases. Eur J Oral Implantol. 2015;8(1):75-88.

28. Katafuchi $M$, Weinstein BF, Leroux BG, Chen YW, Daubert DM. Restoration contour is a risk indicator for peri-implantitis: a cross-sectional radiographic analysis. J Clin Periodontol. 2018;45(2):225-32.

29. Marrone A, Lasserre J, Bercy P, Brecx MC. Prevalence and risk factors for peri-implant disease in Belgian adults. Clin Oral Implants Res. 2013;24(8): 934-40.

30. Aguirre-Zorzano LA, Estefania-Fresco R, Telletxea O, Bravo M. Prevalence of peri-implant inflammatory disease in patients with a history of periodontal disease who receive supportive periodontal therapy. Clin Oral Implants Res. 2015:26(11):1338-44.

31. Canullo L, Penarrocha-Oltra D, Covani U, Botticelli D, Serino G, Penarrocha M. Clinical and microbiological findings in patients with peri-implantitis: a cross-sectional study. Clin Oral Implants Res. 2016;27(3):376-82.

32. Francetti L, Cavalli N, Taschieri S, Corbella S. Ten years follow-up retrospective study on implant survival rates and prevalence of periimplantitis in implant-supported full-arch rehabilitations. Clin Oral Implants Res. 2019;30(3):252-60.

33. Renvert $\mathrm{S}$, Aghazadeh A, Hallstrom H, Persson GR. Factors related to periimplantitis - a retrospective study. Clin Oral Implants Res. 2014;25(4):522-9. 
34. Roos-Jansaker AM, Renvert H, Lindahl C, Renvert S. Nine- to fourteen-year follow-up of implant treatment. Part III: factors associated with peri-implant lesions. J Clin Periodontol. 2006;33(4):296-301.

35. Pimentel SP, Shiota R, Cirano FR, Casarin RCV, Pecorari VGA, Casati MZ, et al. Occurrence of peri-implant diseases and risk indicators at the patient and implant levels: a multilevel cross-sectional study. Journal of Periodontology. 2018;89(9):1091-100

36. Schwarz F, Becker K, Sahm N, Horstkemper T, Rousi K, Becker J. The prevalence of peri-implant diseases for two-piece implants with an internal tube-in-tube connection: a cross-sectional analysis of 512 implants. Clin Oral Implants Res. 2017;28(1):24-8.

37. Monje A, Wang HL, Nart J. Association of preventive maintenance therapy compliance and peri-implant diseases: a cross-sectional study. J Periodontol. 2017;88(10):1030-41.

38. Simonis $\mathrm{P}$, Dufour $\mathrm{T}$, Tenenbaum $\mathrm{H}$. Long-term implant survival and success: a 10-16-year follow-up of non-submerged dental implants. Clin Oral Implants Res. 2010;21(7):772-7.

39. Monje A, Catena A, Borgnakke WS. Association between diabetes mellitus/ hyperglycaemia and peri-implant diseases: systematic review and metaanalysis. J Clin Periodontol. 2017;44(6):636-48.

40. Wu X, Al-Abedalla K, Eimar H, Arekunnath Madathil S, Abi-Nader S, Daniel $N G$, et al. Antihypertensive medications and the survival rate of osseointegrated dental implants: a cohort study. Clin Implant Dent Relat Res. 2016;18(6):1171-82.

41. Schwarz F, Derks J, Monje A, Wang HL. Peri-implantitis. J Periodontol. 2018, 89(Suppl 1):S267-S90.

42. Roos-Jansaker AM, Lindahl C, Renvert H, Renvert S. Nine- to fourteen-year follow-up of implant treatment. Part I: implant loss and associations to various factors. J Clin Periodontol. 2006;33(4):283-9.

43. Merli M, Bernardelli F, Giulianelli E, Toselli I, Mariotti G, Nieri M. Peri-implant bleeding on probing: a cross-sectional multilevel analysis of associated factors. Clin Oral Implants Res. 2017;28(11):1401-5.

44. Farina R, Filippi M, Brazzioli J, Tomasi C, Trombelli L. Bleeding on probing around dental implants: a retrospective study of associated factors. J Clin Periodontol. 2017:44(1):115-22

45. Demmer RT, Papapanou PN, Jacobs DR Jr, Desvarieux M. Bleeding on probing differentially relates to bacterial profiles: the Oral Infections and Vascular Disease Epidemiology Study. J Clin Periodontol. 2008;35(6):479-86.

\section{Publisher's Note}

Springer Nature remains neutral with regard to jurisdictional claims in published maps and institutional affiliations.

\section{Submit your manuscript to a SpringerOpen ${ }^{\circ}$ journal and benefit from:}

- Convenient online submission

- Rigorous peer review

- Open access: articles freely available online

- High visibility within the field

Retaining the copyright to your article

Submit your next manuscript at $\boldsymbol{\nabla}$ springeropen.com 